\title{
Using Explosions to Power a Soft Robot
}

\section{Citation}

Shepherd, Robert F., Adam A. Stokes, Jacob Freake, Jabulani Barber, Phillip W. Snyder, Aaron D. Mazzeo, Ludovico Cademartiri, Stephen A. Morin, and George M. Whitesides. 2013. “Using Explosions to Power a Soft Robot." Angewandte Chemie 125 (10) (March 4): 2964-2968.

\section{Published Version}

doi:10.1002/ange.201209540

\section{Permanent link}

http://nrs.harvard.edu/urn-3:HUL.InstRepos:12388526

\section{Terms of Use}

This article was downloaded from Harvard University's DASH repository, and is made available under the terms and conditions applicable to Open Access Policy Articles, as set forth at http:// nrs.harvard.edu/urn-3:HUL.InstRepos:dash.current.terms-of-use\#OAP

\section{Share Your Story}

The Harvard community has made this article openly available.

Please share how this access benefits you. Submit a story.

Accessibility 


\section{Using Explosions to Power a Soft Robot}

Robert F. Shepherd ${ }^{1}$, Adam A. Stokes ${ }^{1}$, Jacob Freake ${ }^{1}$, Jabulani Barber ${ }^{1}$, Phillip W. Snyder $^{1}$, Aaron D. Mazzeo ${ }^{1}$, Ludovico Cademartiri ${ }^{1}$, Stephen A. Morin ${ }^{1}$, and George M. Whitesides $^{1,2} *$

${ }^{1}$ Department of Chemistry and Chemical Biology, Harvard University, 12 Oxford Street, Cambridge, Massachusetts 02138

${ }^{2}$ Wyss Institute for Biologically Inspired Engineering

60 Oxford Street, Cambridge, Massachusetts 02138

*Corresponding author, email: gwhitesides@gmwgroup.harvard.edu 


\begin{abstract}
This manuscript describes the use of explosions to power a soft robot-one composed solely of organic elastomers (e.g., silicones). The robot has three pneumatic actuators (pneu-nets) in a tripedal configuration. Explosion of a stoichiometric mixture of methane and oxygen within the microchannels making up the actuators produced hot gas that rapidly inflated the pneu-nets, and caused the robot to launch itself vertically from a flat surface (e.g., to jump). A soft flap embedded in the pneu-net acted as the valve of a passive exhaust system, and allowed multiple sequential actuations. The flame and temperature increase from the explosions are short-lived, and do not noticeably damage the robots over dozens of actuation cycles.
\end{abstract}


Soft robots have emerged as a new set of machines capable of manipulation[1-4] and locomotion.[5-8] Pneumatic expansion of a network of microchannels (pneu-nets) fabricated in organic elastomers, using low-pressure air ( $<10 \mathrm{psi} ; 0.7 \mathrm{~atm} ; 71 \mathrm{kPa})$, provides a simple method of achieving complex movements:[1,5] grasping and walking. Despite their advantages (simplicity of fabrication, actuation, and control; low cost; light weight), pneu-nets have the disadvantage that actuation using them is slow, in part because the viscosity of air limits the rate at which the gas can be delivered through tubes to fill and expand the microchannels. Here we demonstrate the rapid actuation of pneu-nets using a chemical reaction (the combustion of methane) to generate explosive bursts of pressure.

Although the combustion of hydrocarbons is ubiquitous in the actuation of hard systems (e.g., in the metal cylinder of a diesel or spark-ignited engine[9]), it has not been used to power soft machines. Here, we demonstrate that explosive chemical reactions[10] producing pulses of high temperature gas for pneu-net actuation provides simple, rapid, co-located power generation, and enables motion, in soft robots. In particular, we used the explosive combustion of hydrocarbons triggered by an electrical spark to cause a soft robot to "jump" (a gait previously only demonstrated for hard systems[11-16]).

We fabricated a tripedal robot (Fig. 1; Fig. S4) using soft lithography.[1] This robot incorporated a passive valving system (Fig. 1a, inset) that allowed us to (i) pressurize the pneunets easily, (ii) exhaust the product gases automatically (without external control), and (iii) actuate the same pneu-net repeatedly. By actuating all three legs simultaneously, we caused the robot to jump more than 30 times its height in less than $0.2 \mathrm{~s}$, at a maximum vertical velocity of $\sim 3.6 \mathrm{~m} / \mathrm{s}$. 
Our choice of explosive chemical reactions for actuation was based on several factors, one being their high volumetric energy density (in units of MJ/L). The energy density of a compressed gas, which we previously used to power soft robots, is $\sim 0.1 \mathrm{MJ} / \mathrm{L}$ at 2,900 psi from the potential for mechanical work, $w$, done by the change in pressure $(\Delta \mathrm{P})$, and volume $(\Delta \mathrm{V})$ when decompressed to atmospheric pressure; combustible gases, like $\mathrm{CH}_{4}$, can also be burned to release heat, $q$, resulting in an energy density of $w+q \sim 8.0 \mathrm{MJ} / \mathrm{L}$ (SI). We used a stoichiometric mixture of methane and oxygen ( 1 mole $\mathrm{CH}_{4}: 2$ moles $\mathrm{O}_{2}$ ) to power the jumps. This stoichiometry minimized the formation of soot, and prevented the contamination of the channels and the clogging of the valves by carbon deposits. We used an electrical spark to ignite the mixture inside the chambers because spark gaps are (i) easily incorporated into soft robots, (ii) controlled in their timing with msec precision, and (iii) faster than other means of ignition (e.g., resistive heating).

We chose pure oxygen instead of air to maximize the energy density of the mixture; air contains only $\sim 21 \mathrm{wt} \% \mathrm{O}_{2}$. Methane was the fuel because it is (i) readily available, (ii) a gas over all temperatures useful for soft robots, and easily pumped through tubing and pneu-nets, (iii) easily controlled to ignite an explosion (i.e., rapid burning) rather than a detonation (i.e., a shock wave),[10,17] (iv) sufficiently exothermic in combustion that it releases enough energy (890 kJ/mol; Eq. 1[18]) for actuation, but not enough to damage the channel or passive valve, and (iv) converted by combustion into products $\left(\mathrm{CO}_{2}(\mathrm{~g})\right.$ and $\left.\mathrm{H}_{2} \mathrm{O}(\mathrm{g})\right)$ that allow rapid depressurization of the actuator at the end of each cycle through a soft microvalve.

$$
\mathrm{CH}_{4(g)}+2 \mathrm{O}_{2(g)} \rightarrow \mathrm{CO}_{2(g)}+2 \mathrm{H}_{2} \mathrm{O}_{(g)}+890 \mathrm{~kJ} / \mathrm{mol}
$$

We fabricated the robot using soft lithography (SI). $[1,5]$ Each leg of the tripedal robot was a hollow chamber with a stoichiometric mixture of $\mathrm{CH}_{4}$ and $\mathrm{O}_{2}$ entering from one side, and gases 
exiting through a valved opening at the other. At the gas-input side of each pneu-net, we placed computer controlled electrodes that triggered a spark (SI).

Explosion Inside an Elastomeric Balloon. The high temperatures of explosive reactions ( $\mathrm{T}>2,500 \mathrm{~K}$ in air[17, 19, 20]) seem incompatible with the low service temperature of silicone elastomers (most degrade at $\mathrm{T}<600 \mathrm{~K}$ ). [21] To a first approximation, the temperature within a pneu-net during the explosion can be estimated using Eq. 2,[20]

$$
\Delta T=\frac{Q}{n_{C O 2} \cdot C_{v}^{C O 2}+n_{H 2 O} C_{v}^{H 2 O}}
$$

where $C_{v}^{C O 2}=28.6 \mathrm{~J} / \mathrm{mol} \cdot \mathrm{K}$ and $C_{v}^{H 2 O}=74.5 \mathrm{~J} / \mathrm{mol} \cdot \mathrm{K}, n_{C O 2}=20 \mu \mathrm{mol}$ and $n_{H 2 O}=40 \mu \mathrm{mol}$, and $Q \approx 18 \mathrm{~J}$ based on our gas-flow rates and channel dimensions; a more detailed analysis (SI) based on Eq. 2 that includes second-order effects predicts a temperature of $3,000 \mathrm{~K}\left(2,800{ }^{\circ} \mathrm{C}\right)$ immediately after ignition. In our pneu-nets, a thin layer of silicone may decompose on exposure to high temperatures,[22] and form a surface layer of silica; this layer may insulate the surface from the radiant heat of the flame.[23]

The duration of the explosion is short. The temperature of the gas is quickly reduced as it expands and the pneu-net inflates. To try and capture the kinetics of the rapid combustion, we used a combination of high-speed infrared (IR) imaging (155 fps; T620; FLIR, Inc.) and bimetallic temperature probes in the interior of a pneu-net. We do not know how the IR intensity detected by the camera partitions between emissions from the hot gas, the surface, and the bulk polymer of the robot, but empirically, three ms after ignition, we detected IR temperature in excess of $500{ }^{\circ} \mathrm{C}$ (Fig. 2a,b). After ten ms, the temperature measured by the IR camera fell below $300{ }^{\circ} \mathrm{C}$ (below the decomposition temperature of silicone; Fig. 2a-d). The IR imaging also 
established that we could actuate a single pneu-net independently, by adjusting the delays between sparks in them (Fig 2e-h).

To measure the temperature of the exhaust gases during a sequence of actuations (one actuation every two seconds; Fig. 2i), we used a thermocouple (SI; Omega Instruments) placed inside the pneu-net. Because the response of the thermocouple is relatively slow, the measurements are averages over tens of milliseconds, and report the temperature of the exhaust gases (which do not exceed peak temperatures of $\sim 125{ }^{\circ} \mathrm{C}$, and cool to $<50{ }^{\circ} \mathrm{C}$ prior to subsequent explosions). In principle, the stability of the $\mathrm{CH}_{4} / \mathrm{O}_{2}$ mixture in the absence of initiating events, and the small increase in temperature in the pneu-nets $\left(\sim 25^{\circ} \mathrm{C}\right.$ above room temperature; SI) after the flame is extinguished, makes these systems safe to handle (Video S1). We emphasize, nonetheless, that a mixture of $\mathrm{CH}_{4} / \mathrm{O}_{2}$ is highly dangerous, and should only be handled by experienced personnel.

Using isothermal nanocalorimetry, we measured the heat evolution during actuation with i) compressed air and ii) combustion of a mixture of $\mathrm{CH}_{4} / \mathrm{O}_{2}$ (Fig. 3; Fig. S2; [24] TA Instruments TAM-III; SI). From the resulting heat measurements and actuation times for compressed air $(\sim 1$ $\mathrm{s}[5])$ and explosions ( $10 \mathrm{~ms}$; Fig. 2a-d), we estimate the power generated by these two actuation methods to be $3.3 \mathrm{~mW}$ and $35 \mathrm{~W}$, respectively. The impulse (change in momentum over time) that results from the $\sim 11,000$ fold increase in power causes rapid actuation of the pneu-nets, and enables the soft robot to jump.

Passive Valve for Release of Exhaust. After the methane has burned in the pneu-net, it is necessary to remove the waste products to ensure an appropriate ratio of $\mathrm{CH}_{4}$ and $\mathrm{O}_{2}$ for the next actuation. To purge the waste $\mathrm{CO}_{2}$ and $\mathrm{H}_{2} \mathrm{O}$ vapor, we embedded exit channels into the ends of 
the legs of the tripod. To actuate a leg, we allowed fresh methane and oxygen to flow into the pneu-net and expel the exhaust gases.

The heat from the combustion reaction increases the pressure of gas in the pneu-net. To limit the expanding gas from leaking before the explosion was complete, we embedded a passive valve — a soft flap molded directly into the pneu-net—immediately before the exit channel (Fig. 1a, inset). At low pressure — before, and 10 ms after, an explosion — the soft valve was open and allowed continuous flow of fuel into the pneu-net, or of waste products out of it. At high pressure - during the explosions - the soft valve closed and caused the pressure to increase and actuate the pneu-net (Fig. 4a; Video S2; SI Text for estimate of pressure during explosion). Approximately seven ms after the spark ignited the $\mathrm{CH}_{4} / \mathrm{O}_{2}$, the pressure generated by the exploding gas caused the leg to inflate (Fig. 4a), and then, $\sim 50 \mathrm{~ms}$ after ignition, to extend $\sim 5$ $\mathrm{mm}$; this extension, in turn, caused the actuator to bend downward (Fig. 4b-e).

Despite the large pressures generated during the explosions, the pneu-nets (fabricated from a stiff silicone rubber, Young's modulus $\sim 3.6 \mathrm{kPa}$; SI) withstood multiple $(>30)$ explosive actuations before failure. These failures typically occurred from the charring of the gas input lines and, occasionally, from tearing of the elastomers at the interface between the actuation layer and the strain-limiting layer.

The toughness and resilience of these silicone elastomers was further evident when we actuated all three legs simultaneously. The tripedal robot contained the three simultaneous explosions and used the energy they generated to jump over 30 times its body height (that is, 30 $\mathrm{cm}$ ) in under $0.2 \mathrm{~s}$ (Fig. 5; Video S3). We used high-speed video to estimate the instantaneous velocity after actuation: the robot jumped $2.5 \mathrm{~cm}$ in $8.25 \mathrm{~ms}$, with a resultant velocity of $3.6 \mathrm{~m} / \mathrm{s}$ $(13 \mathrm{~km} / \mathrm{h})$. The $30 \mathrm{~cm}$ height was, in reality, limited by the height of the safety chamber we used 
to enclose the jumping robot; we estimate that the robot would actually have reached a height of $60 \mathrm{~cm}$ in a taller chamber, and without the weight of the attached tubing (SI).

The use of explosions for actuation is compatible with soft machines. Explosive power allowed a soft robot to jump 30 times its height with an initial speed of $3.6 \mathrm{~m} / \mathrm{s}$; a mobile robot powered by compressed air moved much more slowly (walking at $\sim 0.03 \mathrm{~m} / \mathrm{s}$ ). [5] The siliconebased robot, whose body design we made no attempt to optimize, withstood the tensile forces and temperatures generated by igniting a mixture of methane and oxygen within its pneu-nets. The heat capacity of the robot ( $44 \mathrm{~J} / \mathrm{K}$; SI) was enough to absorb the heat generated from the rapidly burning gas $(\sim 18 \mathrm{~J})$.

Recently, the use of jumping in hard robotic systems (e.g., the "Sandflea" by Boston Dynamics) has been demonstrated as a way to navigate obstacles. We believe that soft robots powered by explosive actuation, with future improvements in design and control,[25] could be autonomous and able to use their ability to jump to navigate obstacles in search and rescue missions; additionally, the cost of these robots ( $\$ 100$; see SI for estimate) would be sufficiently low that they could be considered disposable, with insignificant loss if they were destroyed during use.

The soft robot described in this work can be further developed to convert chemical potential into useful mechanical work (see SI for efficiency calculation). By tailoring the timing in the sparks, it will be possible to increase the jumping height, improve energy efficiency, and direct the jump of the robot. Liquid butane (LB) and other liquid fuels (e.g., gasoline) have even greater volumetric energy densities than gaseous methane, and will be usable as fuels with improved design. 
Acknowledgements. This work was supported by DARPA under award number W911NF-11-1-

0094. The development of materials and the analysis of thermodynamics was supported by a subcontract from Northwestern University on DOE award \# DE-SC0000989. We also thank James McArthur (Department of Physics, Harvard University) for designing the initial sparking board and Marc Strauss (Wyss Institute for Biologically Inspired Engineering) for building it.

\section{References.}

[1] F. Ilievski, A. D. Mazzeo, R. F. Shepherd, X. Chen, G. M. Whitesides, Angew. Chem. Int. Ed. Engl. 2011, 50, 1890-1895.

[2] J. R. Amend, E. Brown, N. Rodenberg, H. M. Jaeger, H. Lipson, IEEE Trans. Robot. 2012, 28, 341-350.

[3] A. Albu-Schaffer, O. Eiberger, M. Grebenstein, S. Haddadin, C. Ott, T. Wimbock, S. Wolf, G. Hirzinger, IEEE Robot. Autom. Mag. 2008, 15, 20-30.

[4] G. Kofod, W. Wirges, M. Paajanen, S. Bauer, Appl. Phys. Lett., 2007, 90, 081916.

[5] R. F. Shepherd, F. Ilievski, W. Choi, S. A. Morin, A. A. Stokes, A. D. Mazzeo, X. Chen, M. Wang, G. M. Whitesides, Proc. Natl. Acad. Sci. U S A. 2011, 108, 20400-20403.

[6] a) A. W. Feinberg, A. Feigel, S. S. Shevkoplyas, S. Sheehy, G. M. Whitesides, K. K. Parker, Science 2007, 317, 1366-1370; b) J. C. Nawroth, H. Lee, A. W. Feinberg, C. M. Ripplinger, M. L. McCain, A. Grosberg, J. O. Dabiri, K. K. Parker, Nat. Biotechnol. 2012, 30, 792-797.

[7] H. T. Lin, G. G. Leisk, B. Trimmer, Bioinspir. Biomim. 2011, 6, 1-14.

[8] D. Trivedi, C. D. Rahn, W. M. Kier, I. D. Walker, Appl. Bionics. Biomech. 2008, 5, 99117.

[9] R. N. Dahms, M. C. Drake, T. D. Fansler, T. W. Kuo, N. Peters, Combust. Flame 2011, 158, 2229-2244.

[10] D. Bradley, P. H. Gaskell, X. J. Gu, Combust. Flame 1996, 104, 176-198.

[11] M. Kovac, M. Fuchs, A. Guignard, J. C. Zufferey, D. Floreano, IEEE Int. Conf. Robot. Autom. 2008, pp. 373-378.

[12] P. Weiss, Sci. News. 2001, 159, 88-91.

[13] S. A. Stoeter, P. E. Rybski, N. Papanikolopoulos, IEEE/RSJ Intl. Conf. on Intelligent Robots and Systems 2002, pp. 721-726.

[14] J. Burdick, P. Fiorini, Int. J. Rob. Res. 2003, 22, 653-674.

[15] R. Armour, K. Paskins, A. Bowyer, J. Vincent, W. Megill, Bioinspir. Biomim. 2007, 2, S65-S82.

[16] H. Tsukagoshi, M. Sasaki, A. Kitagawa, T. Tanaka, IEEE Int. Conf. Robot. Autom., 2005, pp. 1276-1283.

[17] G. E. Andrews, D. Bradley, Combust. Flame 1972, 19, 275-288.

[18] CRC Handbook of Chemistry and Physics, 92 ${ }^{\text {nd }}$ ed., CRC Press, Boca Raton, 2012.

[19] K. Kuo, Principles of Combustion, 2nd ed., John Wiley \& Sons, Hoboken, 2005.

[20] D. Drysdale, An Introduction to Fire Dynamics, John Wiley \& Sons, West Sussex, 1998. 
[21] P. W. Zheng, T. J. McCarthy, Langmuir 2010, 26, 18585-18590.

[22] S. Hamdani, C. Longuet, D. Perrin, J Lopez-cuesta, F. Ganachaud, Polym. Deg. Stab. 2009, 94, 465-495.

[23] F. Y. Hshieh, Fire Mater. 1998, 22, 69-76.

[24] K. J. Laidler, J. H. Meiser, Physical Chemistry, 2nd ed., Houghton Mifflin Company, Boston, 1995, pp. 63.

[25] M. Ahmadi, H. Michalska, M. Buehler, IEEE Trans. Robot. 2007, 23, 553-563. 
Fig. 1. (a) Schematic, including dimensions, of a tripedal soft robot. (a, inset) Soft valves allow low pressure (P1) gas to flow out of the exhaust vents in the pneu-net. High pressure (P2) closes the soft valve. (b) Rendering of the robot with electrical inputs for spark ignition to actuate the pneu-nets explosively. We fed one wire (a common ground) through each of the pneu-nets, and a separate wire into each channel (a positive terminal for high voltage, three total) to allow independent, timed actuation of each leg. Each of the three high-voltage wires was sheathed in tubing that fed premixed methane and oxygen gas into the pneu-nets.

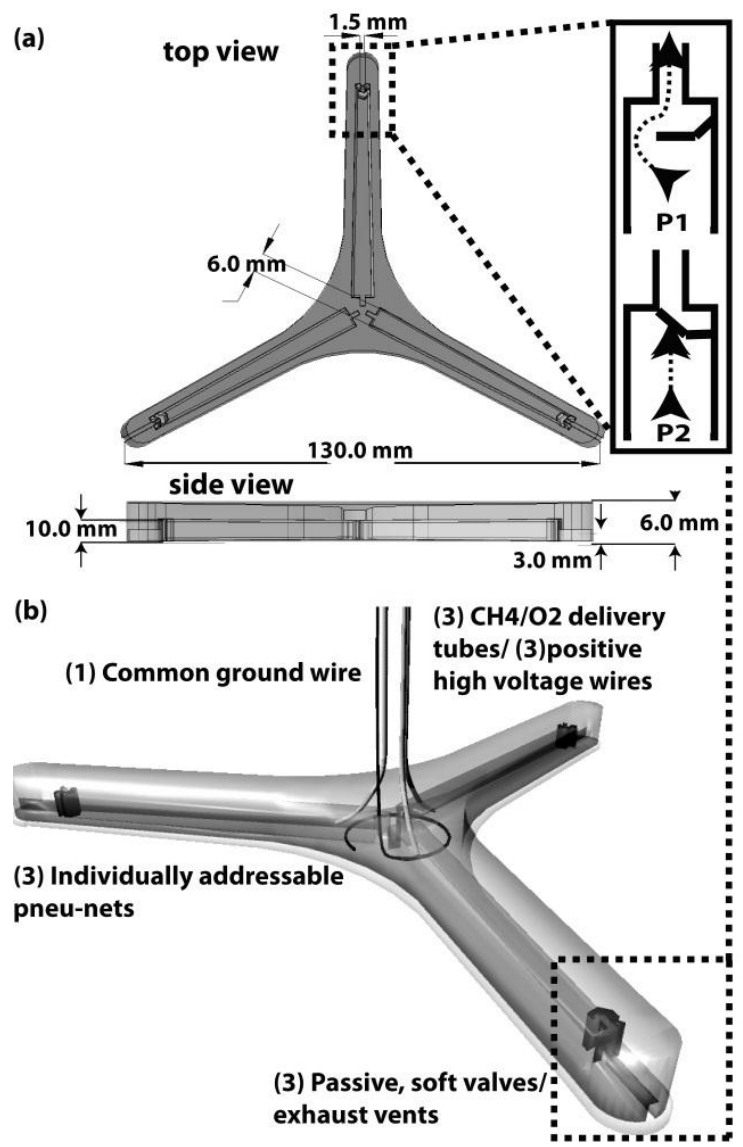


Fig. 2. Infrared images of the top of the robot after (a-d) simultaneous ignition of combustion in all three channels and (e-h) separate actuation of the three pneu-nets with $15 \mathrm{~ms}$ delays between actuations. The channels have an IR signatures below $510{ }^{\circ} \mathrm{C}$ for $6.3 \mathrm{~ms}$; after $9.4 \mathrm{~ms}$, the temperature of the robot is below $340{ }^{\circ} \mathrm{C}$. The colorimetric temperature scale in ${ }^{\circ} \mathrm{C}$. (i) The temperature measured within the pneu-net via thermocouple. (Black) is raw data and (turquoise) is the "averaged" data (using fast Fourier transform smoothing algorithm in Origin ${ }^{\mathrm{TM}}$ graphing software). 

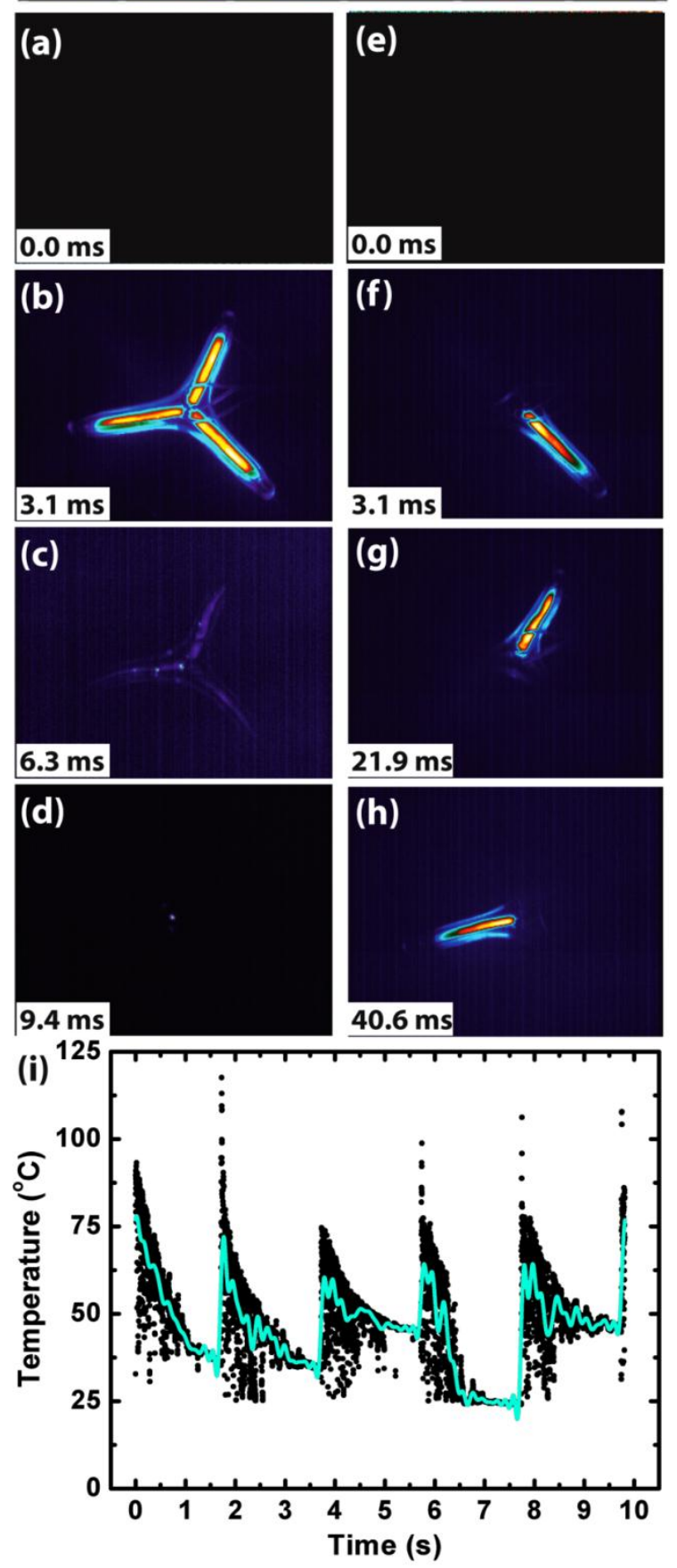
Fig. 3. Calorimetric data for (a) pneumatic actuation of a pneu-net with a $175 \mu \mathrm{L}$ chamber volume. The heat produced (exothermic) while pressurizing the chamber by pumping air into the pneu-net (the area under the first curve) is $3.3 \mathrm{~mJ}$; deactuating the pneu-net by sucking air out and depressurizing the chamber is endothermic and absorbs $2.5 \mathrm{~mJ}$ of heat (area above the second curve). (b) Combustion in the same pneu-net evolves $350 \mathrm{~mJ}$ of heat (area under the heat flow vs. time curve).
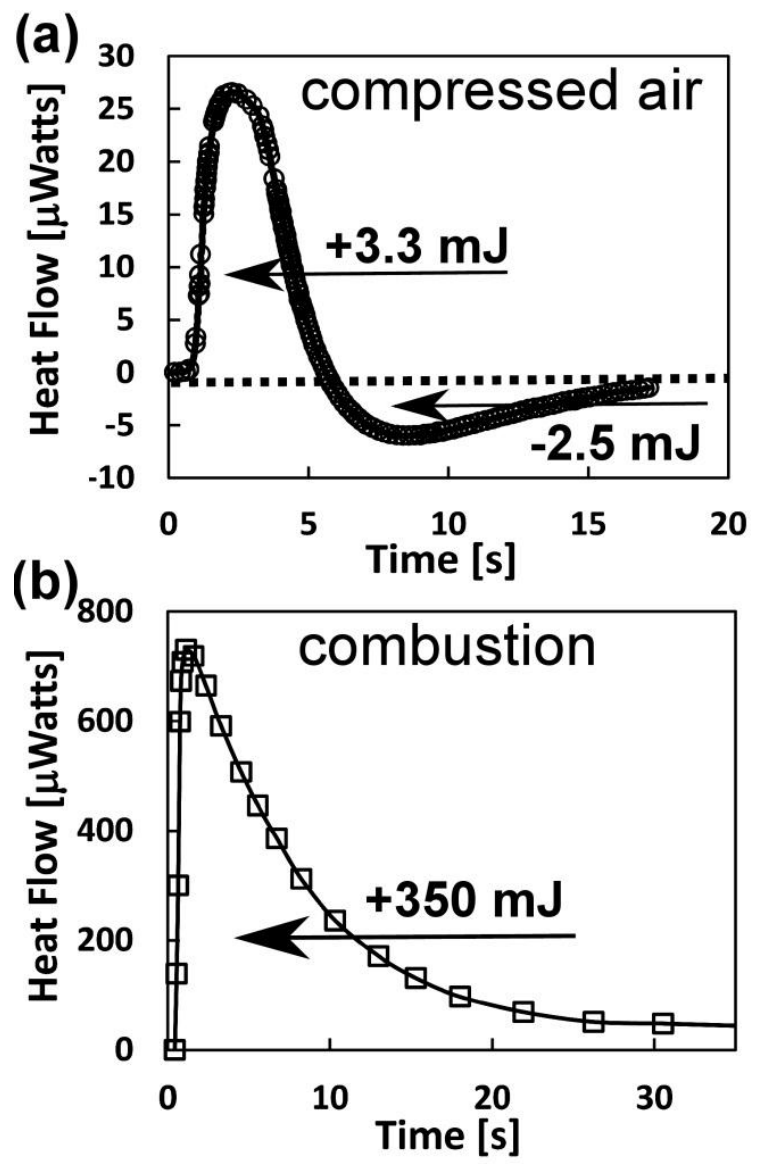
Fig. 4. Optical micrographs of a pneu-net while being explosively actuated, acquired using a high-speed camera. (a) Top view of a leg of the tripod. (Left - Right) An electrical arc (0.0 ms) triggers explosive combustion of methane with a visible flame that persists for $\mathbf{1 0 . 3} \mathbf{~ m s}$. At 7.1 ms, a soft valve prevents propagation of the flame and pressure wave during the explosion After $50 \mathrm{~ms}$, the stored elastic energy stretches the pneu-net. (b) Side view of the tripod before and (c) after ignition of methane oxidation. (d) The flame front propagates to the end of the pneu-nets and (e) the stored elastic energy is released as a downward motion. The dashed line shows the angle of deflection of the robot's feet, at rest. The solid line shows the angle of deflection of the robot under explosive actuation — the rest angle of deflection (dashed line) is overlaid. The scale bar is $2 \mathrm{~cm}$. 

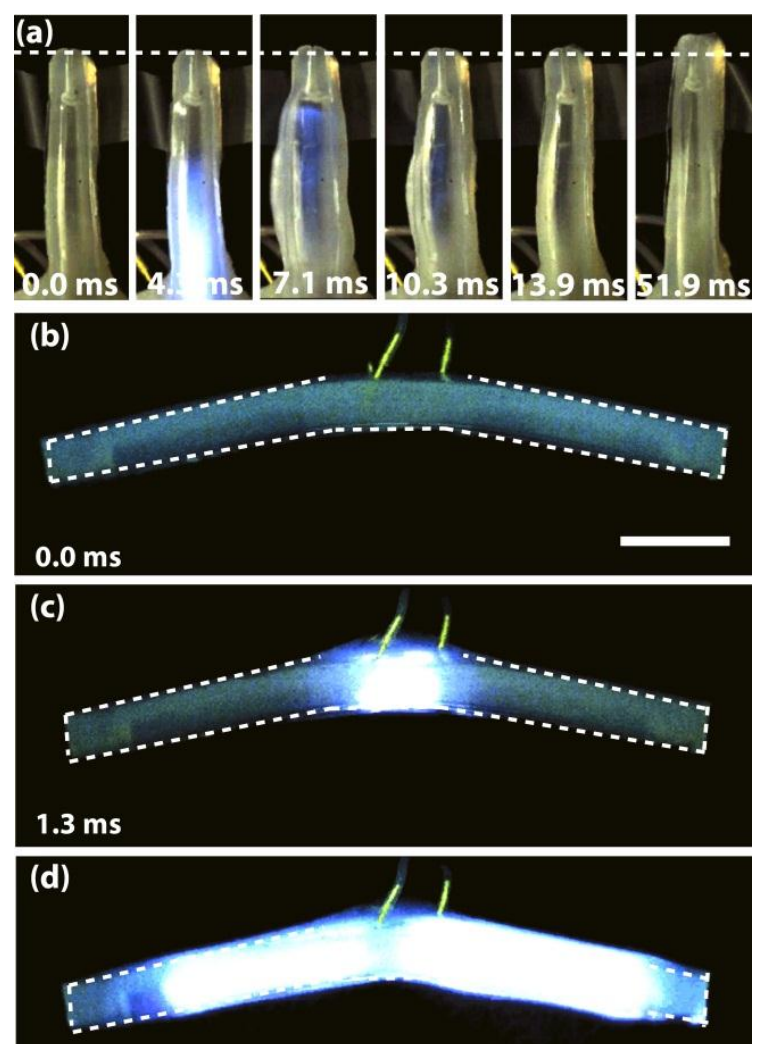

$5.4 \mathrm{~ms}$

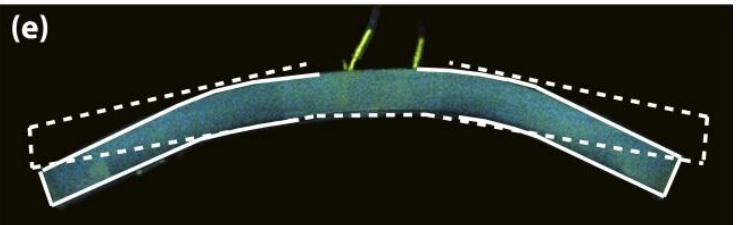

$58.2 \mathrm{~ms}$ 
Fig. 5. Time sequence of a jumping robot. Ignition of all three channels begins at $1 \mathrm{~ms}$. The robot leaps from the ground at $4 \mathrm{~ms}$ and exceeds $30 \mathrm{~cm}$ height after $119 \mathrm{~ms}$. The robot returns to the ground at $368 \mathrm{~ms}$. Tubing and electrical wire is visible in all frames. The scale bar is $15 \mathrm{~cm}$, half the height of the ruler visible in all eight frames. 

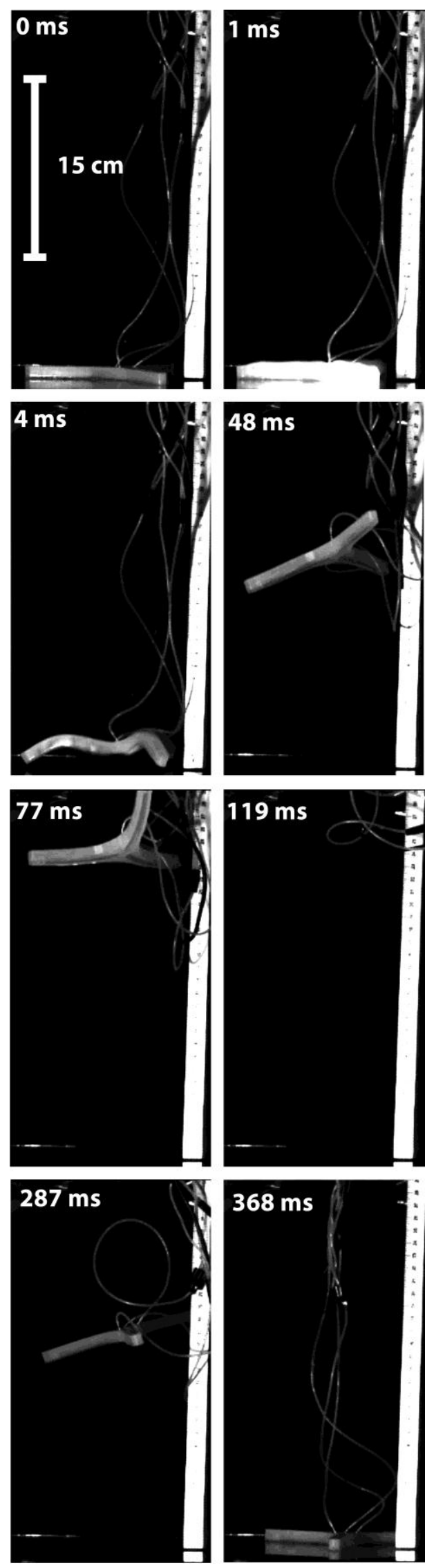


\section{Using Explosions to Power a Soft Robot}

Robert F. Shepherd ${ }^{1}$, Adam A. Stokes ${ }^{1}$, Jacob Freake ${ }^{1}$, Jabulani Barber ${ }^{1}$, Phillip W. Snyder ${ }^{1}$, Aaron D. Mazzeo ${ }^{1}$, Ludovico Cademartiri ${ }^{1}$, Stephen A. Morin ${ }^{1}$, and George M. Whitesides ${ }^{1,2 *}$

${ }^{1}$ Department of Chemistry and Chemical Biology, Harvard University, 12 Oxford Street, Cambridge, Massachusetts 02138

${ }^{2}$ Wyss Institute for Biologically Inspired Engineering

60 Oxford Street, Cambridge, Massachusetts 02138

*Corresponding author, email: gwhitesides@gmwgroup.harvard.edu 
Volumetric Energy Density of Compressed Air and Compressed Methane. Volumetric energy density is a combination of the potential for mechanical work, $w$, done by the change in pressure $(\Delta \mathrm{P})$, and volume $(\Delta \mathrm{V})$, and the chemical heat, $q$, released from burning the gas. For example, compressed air at 2,900 psi ( 197 atm) has an energy density of $0.1 \mathrm{MJ} / \mathrm{L}$ calculated from $\mathrm{P} \Delta \mathrm{V}$ and compressed methane (at 2,900 psi) has an energy density of 8.0 MJ/L calculated from the combination of $\mathrm{P} \Delta \mathrm{V}$ and heat of combustion (Eq. 1).

Estimate of Pressure Immediately After Ignition. Using the unpressurized channel volume of $1.0 \mathrm{~mL}$, and our theoretically estimated temperature immediately after ignition of $2,800{ }^{\circ} \mathrm{C}$, we calculated the maximum pressure, using the ideal gas law, to be $\sim 1 \mathrm{MPa}(\sim 140 \mathrm{psi})$. Though this value is an overestimate (it does not take into account the channel volume expansion and the gas cooling, a complex calculation that is beyond the scope of this paper), we use it to illustrate the quick impulse of high pressure to use a passive valving system to control the flow of gas out of the channel after combustion and cooling.

Fabrication of the Robot. The elastomer we used for the actuation layer was a stiff silicone rubber (Dragon Skin 10, DS-10; Smooth-on, Inc.). This elastomer has a greater Young's modulus than our previous choice for pneumatic actuation (Ecoflex 00-30; Smooth-on, Inc.); pneu-nets composed of DS-10 could withstand the large forces generated within the channels during the explosion better than Ecoflex; in addition, DS-10 has a high resilience, which allowed the pneu-nets to release stored elastic energy rapidly for propulsion (Fig. S1). To seal the pneunet, we bonded a compliant and relatively inextensible silicone rubber (Sylgard 184; Dow 
Corning) to the actuation layer using a thin layer of uncured silicone (Sylgard 184) and then allowed the silicone to cure at room temperature over 12 hours.

We mixed the methane and oxygen gases off-board the robot and injected the mixture, separately, into each leg, at a rate of $12 \mathrm{~mL} / \mathrm{min}$. In order to assure that we delivered a stoichiometric mixture of $\mathrm{CH}_{4}$ and $\mathrm{O}_{2}$, we used mass-flow controllers (100SCCM; MKS Instruments). We used capacitive discharge modules (CDIs), available from the hobby radiocontrolled airplane industry (part\# RCEXL; Paragon RC, Inc.), to generate the large potentials ( $~ 6.6 \mathrm{kV}$ at $2 \mathrm{~mm}$ electrode separation, or $\sim 33 \mathrm{kV} / \mathrm{cm}, 10$ times the approximate breakdown voltage of these gases [1]) to produce the sparks to ignite the gas mixture (Fig. S3). We threaded a single ground wire through all three pneu-nets of the tripod and we threaded the positive electrodes-coaxially-through each of the (three) gas delivery tubes (Figure 1b). We used an Arduino control board to trigger the CDIs to generate the spark between the desired positive electrode(s) and the common ground wire.

Temperature Change and Efficiency. We calculated the temperature change in the explosion of the methane/oxygen mixture $(\Delta \mathrm{T})$ by first calculating the channel volume and therefore the number of moles of carbon dioxide $\left(\mathrm{n}_{\mathrm{CO} 2}\right)$ and water $\left(\mathrm{n}_{\mathrm{O} 2}\right)$ in that volume, as produced by explosion of the stoichiometric mixture of $\mathrm{CH}_{4}$ and $\mathrm{O}_{2}$, assuming standard temperature and pressure. The standard enthalpies of formation of the two products are reported in the literature as $\mathrm{C}_{\mathrm{v}}{ }^{\mathrm{CO} 2}=28.6 \mathrm{~J} / \mathrm{mol} \cdot \mathrm{K}$ and $\mathrm{C}_{\mathrm{v}}{ }^{\mathrm{O} 2}=74.5 \mathrm{~J} / \mathrm{mol} \cdot \mathrm{K}$.

The energy generated by the robot in the system can be calculated using the method outlined in the MATLAB® script below. This calculation uses the mass of the robot (30 grams, excluding external tubing) and the final height of the jump to calculate the potential energy 
generated by the robot using standard Newtonian physics $($ P.E. $=$ mgh). For accuracy the potential energy used in lifting the weight of the feed tubes to the robot is also included. An alternative approach would be to calculate the velocity, $v$, of the robot immediately after it leaves

the surface and use this measure to estimate the kinetic energy $\left(\right.$ K.E. $\left.=1 / 2 \mathrm{mv}^{2}\right)$. We implemented this approach using high speed video analysis, and the resulting energies (P.E. = 0.13 J vs. K.E. $=0.20 \mathrm{~J}$ are within the right order of magnitude as a good check. The chemical energy developed in the combustion of $20 \mu \mathrm{mol}$ of methane and $40 \mu \mathrm{mol}$ of oxygen is $\sim 18 \mathrm{~J}$, as calculated using enthalpy of combustion of methane (from the standard enthalpies of formation of the products). We used this value to estimate the efficiency of the system; efficiency = (mechanical energy out / chemical energy in)*100\%, which we evaluated as $\sim 0.7 \%$.

\section{Measurement of the Heat Evolution During Explosive Actuation Using Nanocalorimetry. The} nanocalorimeter we used ( 1 nanoWatt sensitivity) measures the heat flow in units of $(\mu \mathrm{J} / \mathrm{s})$ as a function of time, and the integral of this curve is the heat $(q)$ evolved or absorbed [2]. Due to the volume constraint of the cylindrical cell of the calorimeter (the cylinder was $1 \mathrm{~cm}$ in diameter by $5 \mathrm{~cm}$ long cylinder) we used a smaller actuator volume $(125 \mu \mathrm{L})$ than the one we used for the jumping robot $(1.5 \mathrm{~mL})$.

To measure the heat evolved by actuation with compressed air, we assume that the calorimeter is adiabatic, and thus the $q$ we measure is equivalent to the mechanical work, $-w$, done by the pneu-net including frictional losses. We determined $-w$ by injecting $750 \mu \mathrm{L}$ of air via a syringe pump (Harvard Apparatus), the pressure within the pneu-net increased by $\sim 1$ psi and we detected a $q=-3.3 \mathrm{~mJ}$ (Fig. 3a). After actuation, the pneu-net then slowly leaked air into the larger volume calorimeter cell (via diffusion through the porous silicone[3]) and we 
measured the heat absorbed (from the expansion of gas and coiling of the polymer chains) during the de-actuation to be $q=2.5 \mathrm{~mJ}$ (Fig. 3a). There is thus an $18 \%$ loss in converting the potential energy of the compressed gas into mechanical work in the actuator.

In the second experiment, by threading electrical wire into the calorimeter cell, we were able to trigger the combustion of premixed methane/oxygen gas inside the small pneu-net. We filled the volume of the pneu-net with stoichiometric methane/oxygen and triggered an explosion. The heat evolved during the combustion of the gas was $q=350 \mathrm{~mJ}$ (Fig. $3 \mathrm{~b}$ ).

The actuation time for compressed air to drive the $125 \mu \mathrm{L}$ pneu-net is $\sim 1$ second[4]; the resulting power supplied to the pneu-net is $3.3 \mathrm{~mJ} / 1 \mathrm{~s}=3.3 \mathrm{~mW}$. The time required for an explosion to actuate the small pneu-net is $\sim 10 \mathrm{~ms}$ (Fig. $2 \mathrm{a}-\mathrm{d}$ ), yielding $350 \mathrm{~mJ} / 10 \mathrm{~ms}=35 \mathrm{~W}$ of power. The impulse (change in momentum over time) that results from the $\sim 11,000$ fold (35 $\mathrm{W} / 3.3 \mathrm{~mW}$ ) increase in power causes rapid actuation of the pneu-nets and a jump of the soft robot.

Thermocouple Description. We used a platinum/rhodium thermocouple from Omega Instruments to measure the internal temperature of the pneu-nets during explosive actuation.

Jumping Height Calculations. With a measured initial velocity of $3.6 \mathrm{~m} / \mathrm{s}$ leaving the ground, the maximum attainable height of an unrestrained robot with a constant mass would be $66 \mathrm{~cm}$ (square of the initial velocity divided by twice the constant for gravitational acceleration). Nevertheless, the robot only reached a height of $30 \mathrm{~cm}$ because it hit the top of the safety container in which it jumped. When reaching a height of $30 \mathrm{~cm}$, an untethered robot under idealized conditions would arrive in $90 \mathrm{~ms}$ and still have an upwards velocity of $2.7 \mathrm{~m} / \mathrm{s}$ (square 
root of the difference between the square of the initial velocity and twice the product of the height and constant for gravitational acceleration). In reality, the robot required $150 \mathrm{~ms}$ (over $60 \%$ more time than that predicted) to reach the height of $30 \mathrm{~cm}$ because tethered tubing added mass to the robot as it was rising.

Adiabatic Flame Temperature. We also estimated the adiabatic flame temperature with constant pressure (constant enthalpy) for this chemical reaction. The "frozen flame temperature" as described by Kuo [5] was 5,690 K $\left(5,417^{\circ} \mathrm{C}\right.$; see Matlab Script). In reality, the adiabatic flame temperature is much less because of dissociations of the products in the combustive reaction. According to Kuo, estimates for "frozen flame temperature" are generally valid for temperatures less than 1,200 K. For cases above 1,200 K, an adiabatic flame calculator (http://elearning.cerfacs.fr/combustion/tools/adiabaticflametemperature/index.php) is helpful. We used a pressure of $1 \mathrm{~atm}$, an initial temperature of $298.15 \mathrm{~K}$, fuel species of $\mathrm{CH}_{4}$, an air molar ratio of 0 , and an equivalence ratio of 1 , and the computed adiabatic flame temperature was 3,052 K. This value represents a lower limit of temperature because our process is not isobaric.

Estimate for Average Change in Temperature of the Robot Itself. The specific heat of PDMS is $1.46 \mathrm{e} 3 \mathrm{~J} /(\mathrm{kg} \mathrm{K})$ and the robot is composed of $30 \mathrm{~g}$ of silicone, and thus has a net, equilibrated heat capacity of $\sim 45 \mathrm{~J} / \mathrm{K}$. The average change in temperature, for the actuation of all its legs is then the difference of the heat generated from the methane combustion (Q; Matlab script below) and the mechanical energy from the jump (U; Matlab script below) divided by the heat capacity. The average change in temperature is thus $\sim 0.41 \mathrm{~K}$ for simultaneous actuation of all three legs. 
Cost Estimate for Untethered Jumping Robot. The minimum requirements for untethered jumping are one solenoid valve for metering gas ( \$25; McMaster-Carr, product \# 7877K311), a control board ( \$25; Arduino Uno; Mouser Electronics, product \#782-A000066), an ignition system ( \$50; RC Extreme Power, Inc., single cylinder). The material costs (e.g., silicone, methane, hydrogen peroxide for oxygen, or simply oxygen or air) and battery are negligible compared to the electronics costs.

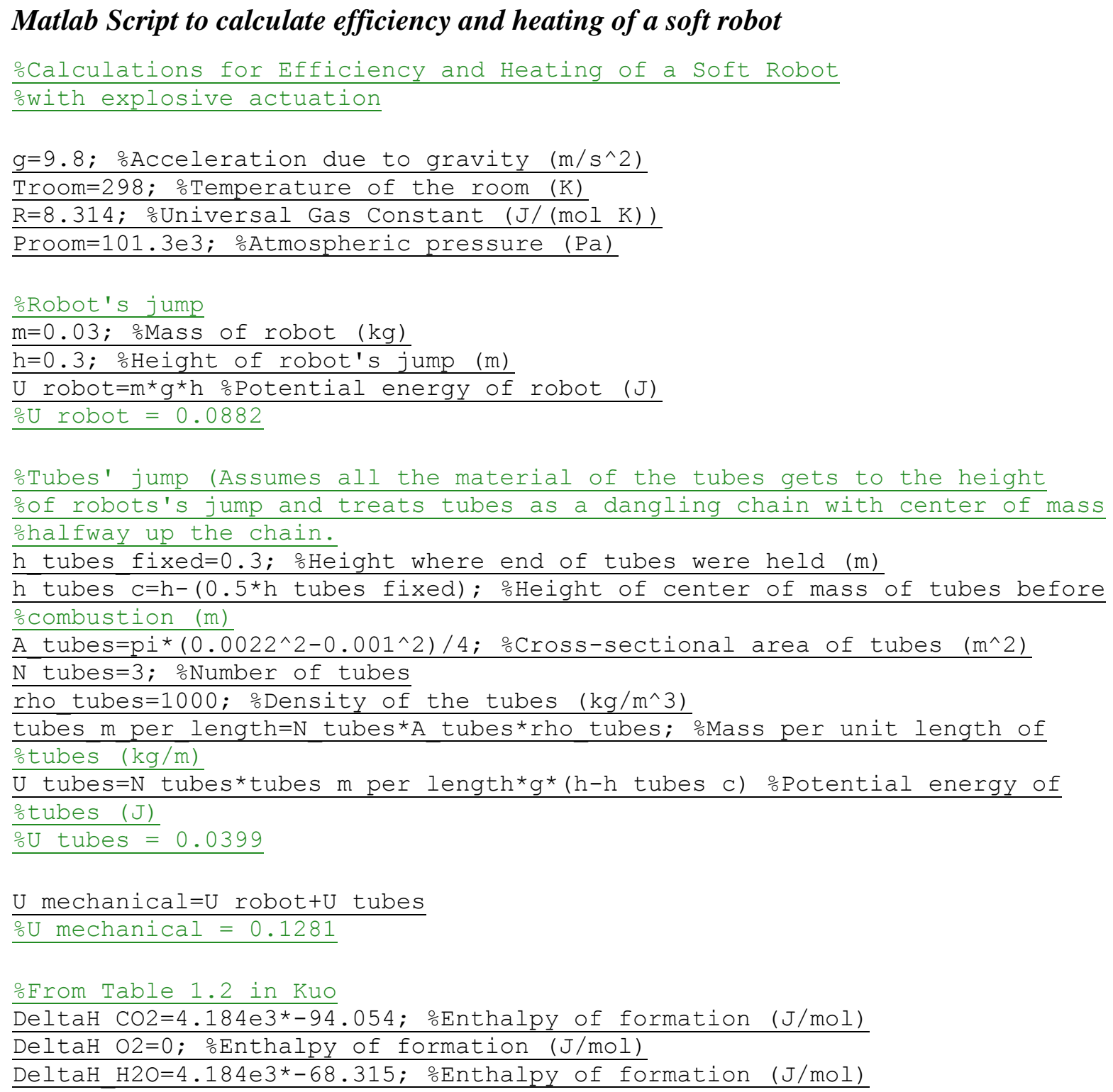


DeltaH CH4=4.184e3*-17.895; Enthalpy of formation ( J/mol) DeltaH combustion=DeltaH CO2+2*DeltaH H2O-DeltaH CH4 \%Enthalpy of ocombustion ( J/mol)

oDeltaH combustion $=-8.9031 e+005$

Vol CH4=0.5e-3; Volume of combusted methane at 298K and 1 atm (liters)

n CH4=101.3e $3 * \operatorname{Vol~CH} 4 * 1 e-3 /(8.314 * 298) \div$ Number of moles of methane before ocombustion (mol)

on $\mathrm{CH} 4=2.0443 e-005$

$\mathrm{Q}=-\mathrm{n}$ CH4*DeltaH combustion oEnergy given off through combustion

$\% \mathrm{Q}=18.2009$

PercentageEfficiency=U mechanical/Q*100

oPercentageEfficiency $=0.7038$

oEstimate for average change in temperature of the robot itself

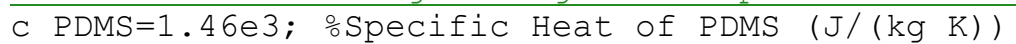

AveDeltaT robot $=(\mathrm{Q}-\mathrm{U}$ mechanical $) /\left(\mathrm{m}{ }^{*} \mathrm{C}\right.$ PDMS $)$

oAveDeltat robot $=0.4126$ 


\section{References.}

[1] CRC Handbook of Chemistry and Physics, 92 ${ }^{\text {nd }}$ ed., CRC Press, Boca Raton, 2012.

[2] K. J. Laidler, J. H. Meiser, Physical Chemistry, 2nd ed., Houghton Mifflin Company, Boston, 1995, pp. 63.

[3] F. Ilievski, A. D. Mazzeo, R. F. Shepherd, X. Chen, G. M. Whitesides, Angew. Chem. Int. Ed. Engl. 2011, 50, 1890-1895.

[4] R. F. Shepherd, F. Ilievski, W. Choi, S. A. Morin, A. A. Stokes, A. D. Mazzeo, X. Chen, M. Wang, G. M. Whitesides, Proc. Natl. Acad. Sci. U S A. 2011, 108, 20400-20403.

[5] K. Kuo, Principles of Combustion, 2nd ed., John Wiley \& Sons, Hoboken, 2005. 
Fig. S1. Stress vs. strain curves of Ecoflex 0030 and Dragon Skin 10.

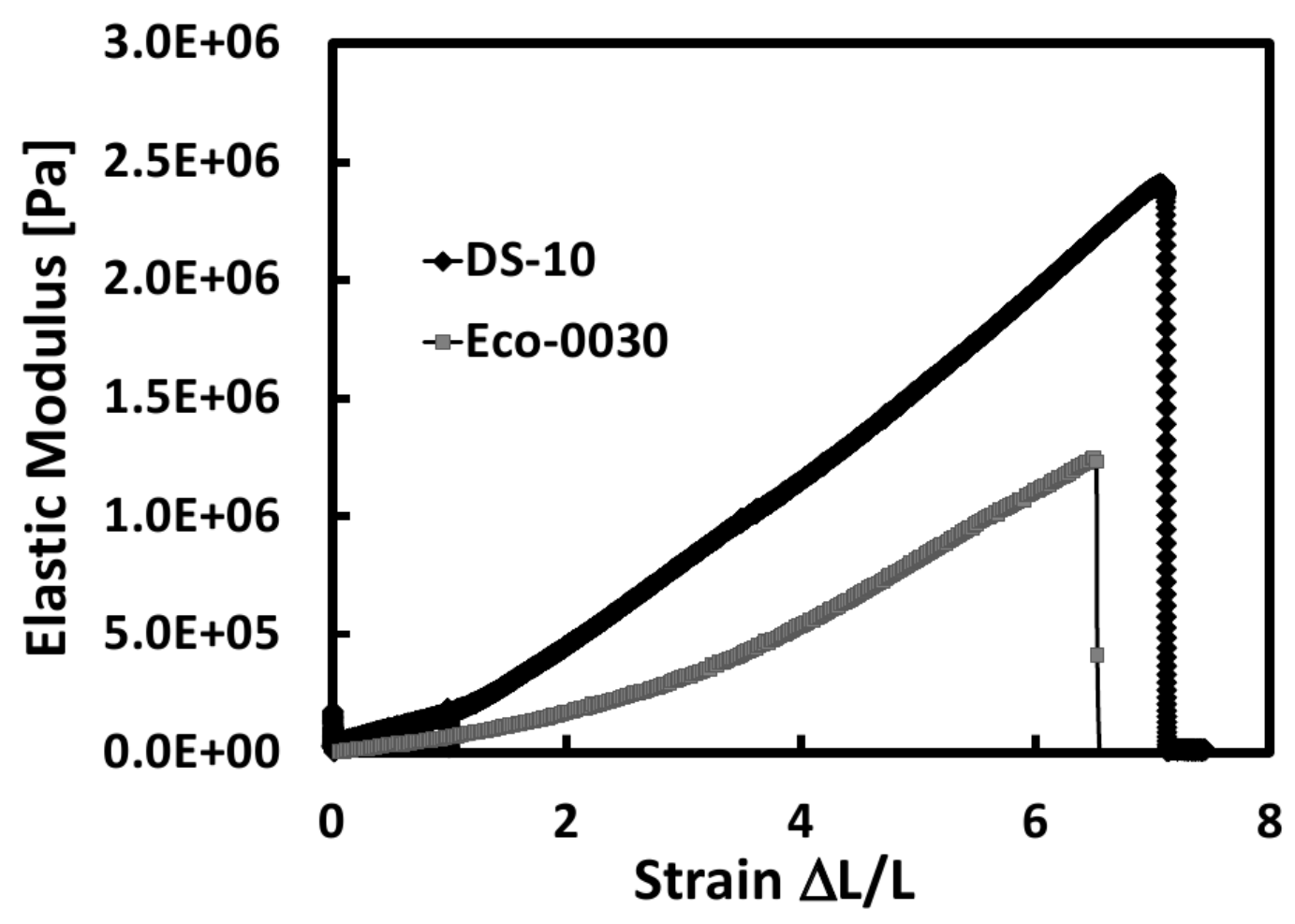


Fig. S2. Schematic of an isothermal calorimeter for measuring combustive actuation in a pneunet. $\mathrm{CH}_{4}: \mathrm{O}_{2}$ is pumped into the pneu-net and out through an exit channel. Ignition leads trigger an electrical arc that ignites the gas mixture after the desired amount of equilibration time for the calorimeter. The external water bath is held at constant temperature and the difference in temperatures between the internal and external water baths is used to determine the heat flux during a reaction in the reaction cell (white box, center). This figure was inspired by that in Laidler \& Meiser [2].

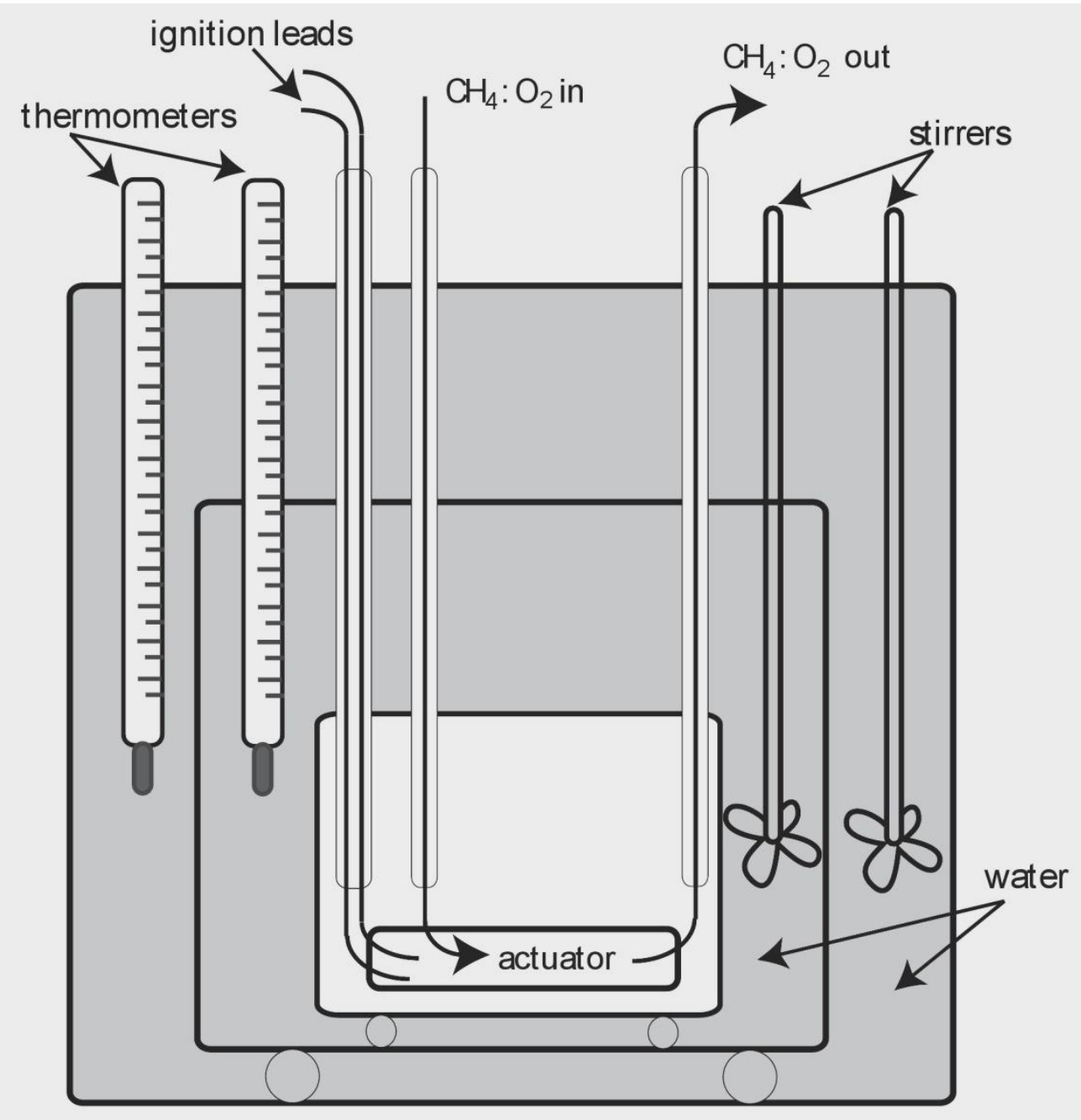


Fig. S3. (a) Photograph of ignition system and (b) schematic diagram of ignition system.

(a)

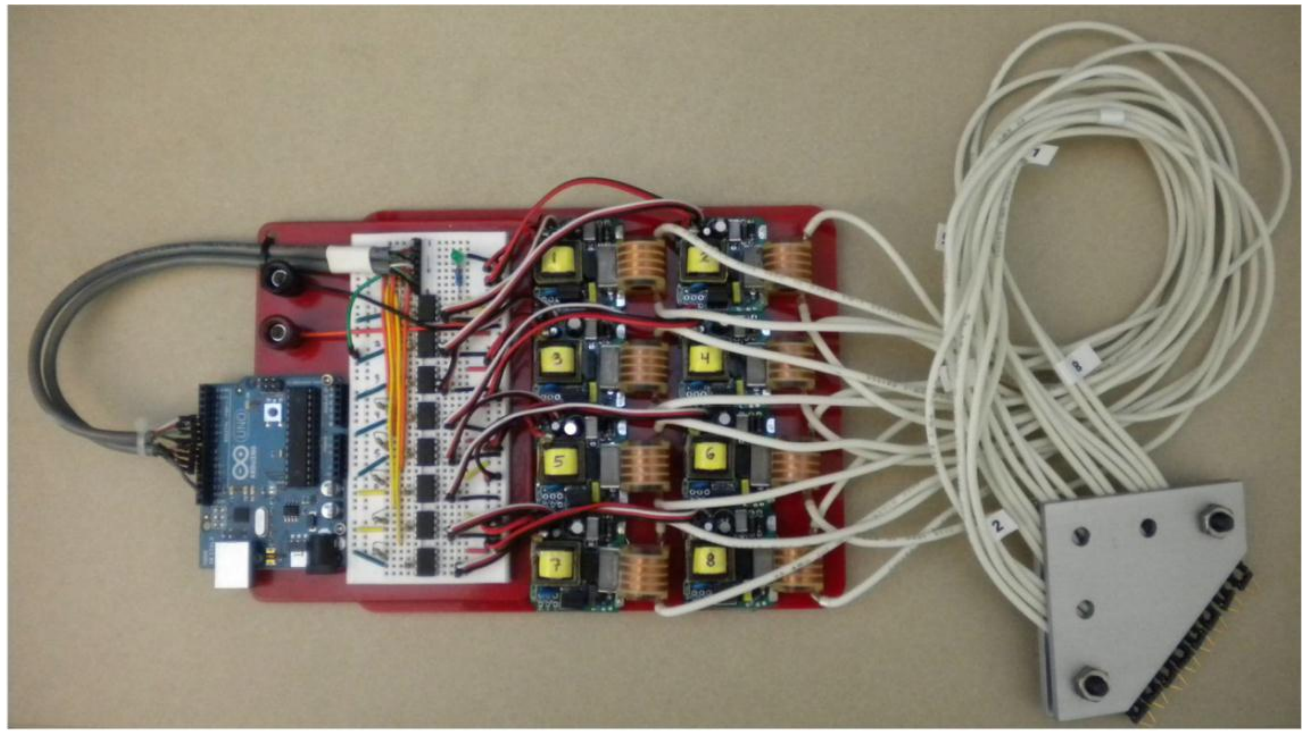

(b)

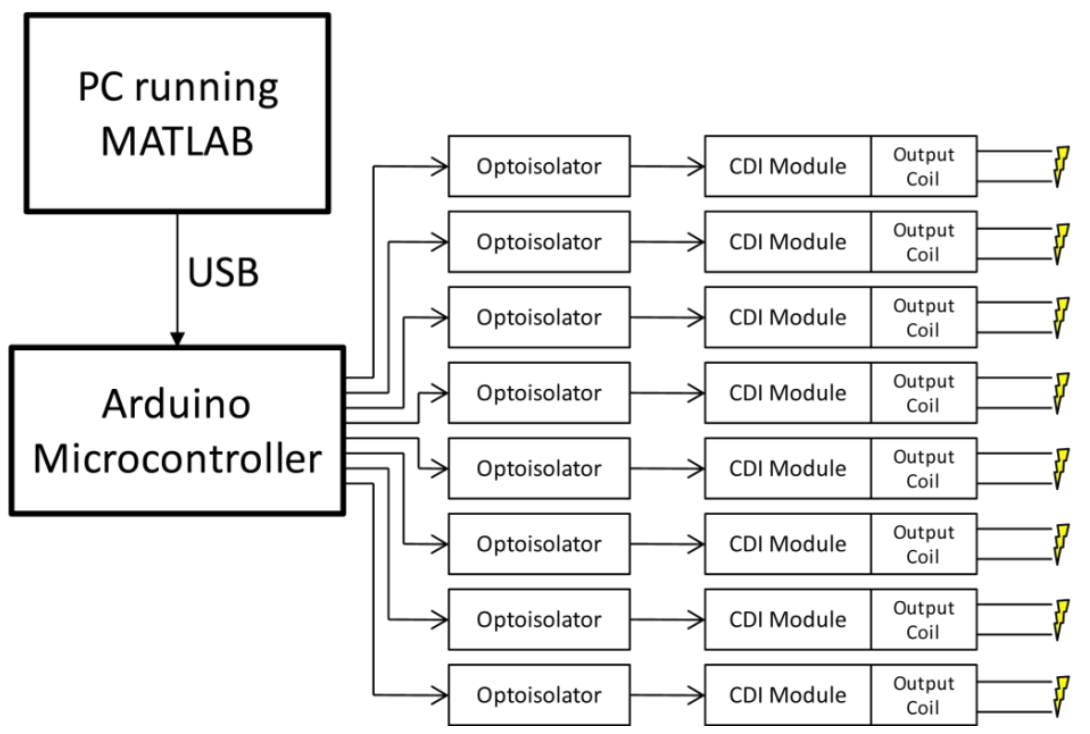


Fig. S4. Engineering schematics of jumping robot. Dimensions in millimeters.

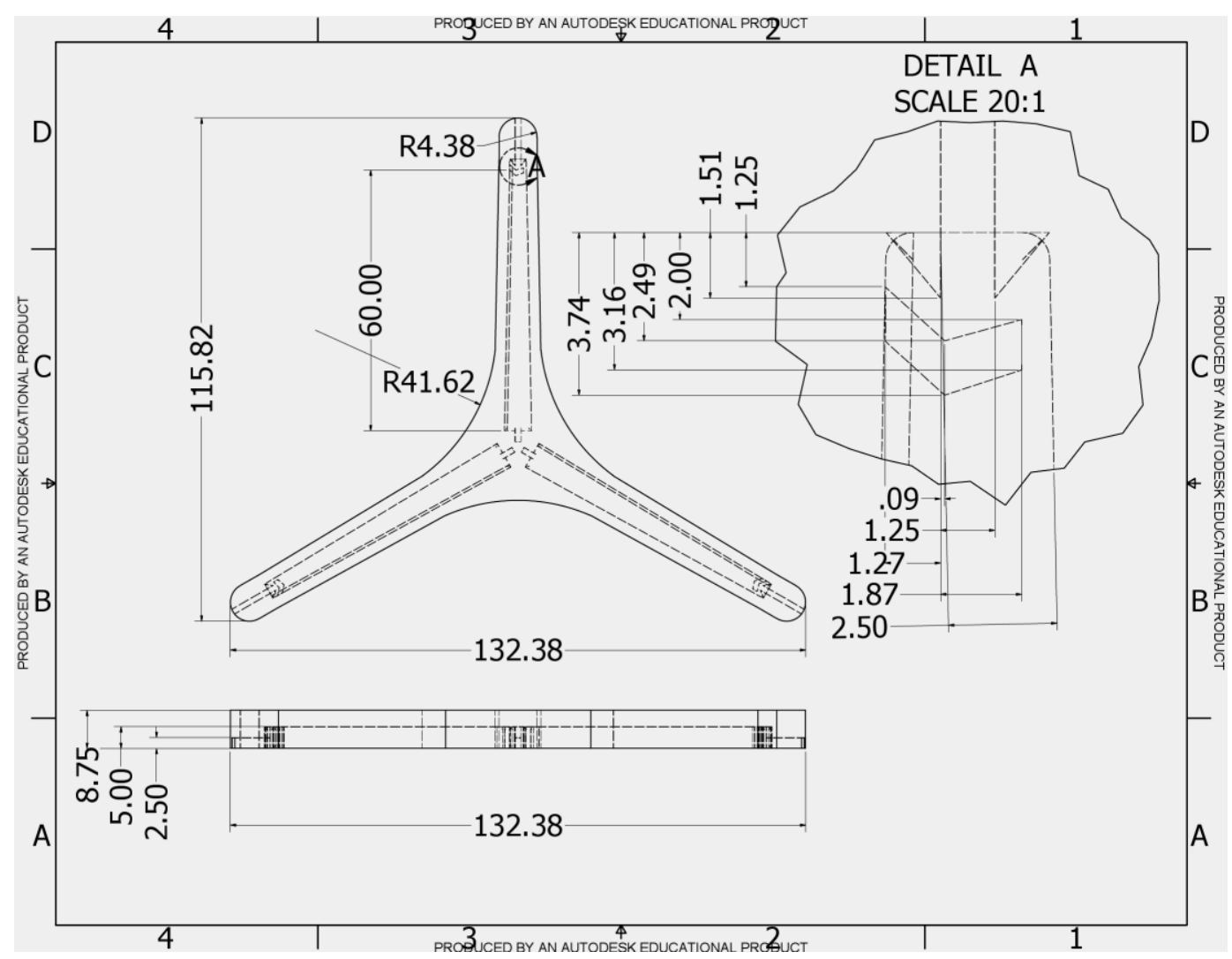


Video S1. This video demonstrates that the mini explosions are small enough for the robots to be handled by experienced personnel only. https://www.dropbox.com/s/r14d1xkunsq8hat/VideoS1.MOV

Video S2. This video demonstrates the passive valve automatically closing and opening during explosive actuation.

https://www.dropbox.com/s/m0x8dt41 pivmil6/VideoS2.MOV

Video S3. This high-speed video shows the robot jumping over thirty times its height in $\sim 119 \mathrm{~ms}$. https://www.dropbox.com/s/wht6d9fxt7vgx1v/VideoS3.wmv 